\title{
What Counts in the Acquisition and Attrition of Numeral Classifiers?
}

\author{
Lynne Hansen \\ Brigham Young University, Hawaii
}

\author{
Yung-Lin Chen \\ Brigham Young University, Hawaii
}

This study compares second language (L2) acquisition and attrition sequences of the syntax and semantics of numeral classifier systems in light of considerations of markedness, frequency, and the regression hypothesis. In classifier data elicited from English-speaking adult learners and attriters of two East Asia languages, Japanese and Chinese, we find in the attrition of both languages, in both syntax and semantics, a regression of the acquisition sequence. An implicational semantic scale, the Numeral Classifer Accessibility Hierarchy, coinciding closely with the relative frequencies of the classifiers in input, appears to provide a path of least resistance for the learning and the loss of the semantic systems.

本研究では、有標性、頻度、回帰仮説の観点から、助数詞・分類辞を取り上 け、統語的・意味的に第二言語習得・製失の順序を考察した。二種類の言語

(日本語・中国語) について、成人の言語学習者・袈失者加ら助数詞・分類辞 のテータを収集し、二種類の言語の㹂失、統語的・意味的習得と裴失、習得順 位について考察した。含意の意味的スケール、助数詞・分類辞の容認可能性 の階層、インブットに現れる助数詞・分類辞の頻度は互いに関倸しており、阻 害が最小になるような習得過程や、言語坟失過程を示咬していることが考えら れる。

$\mathrm{T}$ his paper examines interlanguage classifier systems, an as pect of second language (L2) semantics and lexicon that has scarcely been touched upon in previous research. The focus is on the accessibility of numeral classifiers in the learning and subsequent forgetting of two East Asian languages by English-speaking adults. The aims of the investigation are (a) to determine the stages of classifier syntax in learning and loss, (b) to examine semantic accessibility in classifier systems in learning and loss, and (c) to explain the findings in light of considerations of markedness, frequency, and the regression hypothesis. A comparison of data from two groups within the same population who learned unrelated languages, Japanese or Chi- 
nese, increases the transparency of the window that is provided into universals in second language progression and regression.

\section{Numeral Classifier Systems}

The languages of the world can be divided into two groups with regard to numeral classifiers: those that have classifiers, such as the majority of languages in East and Southeast Asia, and those that do not, such as most European languages, including English (Allan, 1977). In Japanese and Chinese the numeral classifiers, or "counters" as they are also called, are morphemes which occur adjacent to numerals and categorize the noun referent based on semantic features such as animacy, shape, size, arrangement, and function. A counter is obligatory in a noun phrase containing a numeral, and, as shown in the following examples, occurs between the number and the noun referent:

$\begin{array}{llllll}\text { (1) English } & \text { three } & & \text { books } \\ \text { (2) Japanese } & \begin{array}{l}\text { san } \\ \text { (three }\end{array} & \begin{array}{l}\text { satu } \\ \text { classifier }\end{array} & \begin{array}{l}\text { no } \\ \text { poss. part. }\end{array} & \begin{array}{l}\text { hon } \\ \text { book) } \\ \text { (3) Mandarin }\end{array} \\ \begin{array}{llll}\text { san } \\ \text { (three }\end{array} & \begin{array}{l}\text { ben } \\ \text { classifier }\end{array} & \text { book) }\end{array}$

There are scores of such counters in both Japanese and Chinese which co-occur only with nouns that share the semantic feature specified by that classifier. In the schematic organizations of the Japanese and Mandarin classifier systems shown in Appendix I, we include the particular classifiers that are examined in the present study. While these two systems have many similarities, they do differ in the details of the semantic classifications as well as in the amount of variability allowed in reference. Chinese noun classes are more variable than those in Japanese, with a greater tendency for fuzzy sets that are often mutually overlapping.

The research on the semantics, frequency, and historical development of classifiers in many languages has established an implicational scale of the semantic features of classification (Craig, 1986). This scale is derived from cross-linguistic investigations such as Adams and Conklin's (1973) study of the classifier inventories of 37 Asian languages. This study reports that animacy, in the form of a human/nonhuman distinction or an animate/inanimate distinction, is always encoded. The three basic shape categories of long, round, and flat usually appear also. Secondary parameters, such as rigidity and size, are often found but usually in combination with the primary parameters 
instead of serving as the sole basis for classification. Functional parameters such as tools, footwear, and written materials also appear frequently, but, unlike the parameters of shape and animacy, are quite language-specific, reflecting the interests of members of the particular culture in which the language is spoken. The points on the implicational scalc of semantic features, the Numeral Classifier Accessibility Hierarchy (NCAH), are ordered as follows:

$$
\text { Animate human }>\text { Animate non human }>\text { Shape }>\text { Function }
$$

In applying this hierarchy of markedness to the issues raised in the present study, we hypothesize that the accessibility of classifiers in acquisition and attrition follows the order of this implicational scale. That is, we expect the least marked distinction, animate: human, to be the earliest to appear and the longest to be retained, and the distinction at the end of the scale, function, to be the last to appear and the earliest to be lost after the onset of attrition.

\section{Acquisition of Numeral Classifiers}

A number of first language (L1) studies have examined the acquisition of numeral classifiers by children in several Asian languages: Japanese (Clancy, 1986; Matsumoto, 1985; Sanches, 1977), Chinese (Erbaugh, 1986; Hu, 1993; Ken, 1991), Garo (Burling, 1973), and Thai (Carpenter, 1991; Gandour, Petty, Dardarananda, Dechongkit \& Mukangoen, 1984). In Japanese the first two classifiers learned are the general inanimate (tu), and the human classifier (nin), followed by the counters for flat, thin objects (maí), small animals (hiki), long slender objects (hon), small three-dimensional objects ( $k o$ ), and vehicles (dai) (Sanches, 1977; Matsumoto, 1985; Downing, 1996). After these basic forms are acquired, Sanches (1977) reports the acquisition of the classifiers for books (satu) and for birds and rabbits (wa), followed by the counters for buildings (ken) and small boats (soo). For Chinese, Hu (1993) found that small children acquire the Chinese classifiers denoting animacy earlier than classifiers denoting shape and function, as predicted by considerations of markedness and language universals. In fact, the L1 Chinese children learned to draw a distinction between animates and inanimates as early as three years of age. Hu also reported that the children tended to use this general classifier more than specific ones.

In their comparative study of L1 Japanese and Chinese classifiers, Uchida and Imai (in press) outline three stages of acquisition. In the first, children fail to supply a classifier. In the second, they become aware of the grammatical role of classifiers but still lack the knowl- 
edge to differentiate usage of the classifiers, which results in rampant overgeneralization. Gradually the children proceed to the third stage in which the semantic rules for each classifier are sorted out.

The present line of inquiry (Hansen \& Davies, 1998; Chen, 1999; Hansen \& Chen, 1999) is the first to investigate the accessibility of numeral classifiers in $\mathrm{L} 2$ learning and loss in adults.

\section{The Regression Hypothesis}

Since the study of language attrition is relatively recent (for overviews of this sub-field of applied linguistics, see de Bot \& Weltens, 1995; Hansen \& Reetz-Kurashige, 1999; Hansen, 2000a, 2000b, in press), much more is known about the sequences of language learning than of language loss. In the second language acquisition field, interlanguage, the language of $\mathrm{L} 2$ learners, is seen as a series of stages that all learners pass through in acquiring a language. In language attrition, the regression hypothesis is the idea that, in losing a language, attriters will follow an order opposite to the stages of acquisition. Dating back to Jakobson (1968), the hypothesis describes the path of language loss as the mirror opposite of acquisition, with the last learned being the first forgotten, the first learned being the longest retained (for a review of regression theory, see de Bot \& Weltens, 1991).

In the language attrition literature the regression hypothesis has been supported in a general sense at the inter-linguistic skills level: receptive skills precede productive skills in acquisition and the reverse holds true for attrition. At the intra-linguistic level (within morphology, syntax, semantics, and the lexicon), however, documenting that the stages of development are reversed in attrition is more difficult. Tracking both acquisition and attrition is time consuming and a universal or predictable developmental ladder has been established for only a limited number of linguistic structures. However, a number of studies have demonstrated through testing that the regression hypothesis holds (Cohen, 1975; Berman \& Olshtain, 1983; Olshtain, 1989; Hansen, 1999). In a longitudinal study of the acquisition and attrition of negation in Hindi-Urdu by two American children, Hansen (1980, p. 169) concludes that "the forgetting data from both children could be interpreted as a recapitulation in reverse of the acquisitional sequence." Kuhberg's (1992, p. 138) longitudinal L2 acquisition and attrition study of three Turkish children's German found that "attrition was largely a mirror image of acquisition: First learned, basic syntactic patterns were retained longest." As Yoshitomi (1992, p. 295) cautions, however, "the generalizability of reverse order [the regression hypothesis] at the intra-skills level is limited because the hypothesis has been tested on only 
a limited number of specific syntactic structures."

\section{Research Focus}

In examining the acquisition and attrition accessibility of numeral classifier systems, the present study looks for evidence of regression in semantics and the lexicon as well as syntax. The research questions are:

1. What are the stages in the learning and loss of numeral classifier syntax in Japanese and Chinese by English-speaking adults?

2. What are the sequences of semantic accessibility?

3. To what extent are the accessibility sequences of the numeral classifiers explained by considerations of language universals and frequency in input?

4. Does classifier accessibility in attrition follow a reverse order to that of acquisition?

\section{Method}

\section{Subjects and Data Collection}

The subjects included two groups of learners and attriters from the same population. They were native speakers of English in the western United States who, as young adults, had worked (or, in the case of the learners, were working) as full-time missionaries in Japan or Taiwan. Immersed in the culture of their target language, Japanese or Mandarin Chinese, they had acquired (or were acquiring) fluent competence in the spoken language through daily interaction with native speakers. The length of time spent in the target culture by the subjects varied from as little as 18 months (for females over the past two decades) to as long as three years (for males before 1959). Upon completion of their missions, the attriters (those who were or would be losing their L2) returned to an English environment in the western United States where L2 exposure was discontinued or greatly reduced.

The L2 Japanese learner/attriter group consisted of 204 learners ( 153 male, 51 female), 189 attriters ( 138 male and 54 female), and a control group of 14 native speakers of Japanese. The learners in Japan were selected randomly at missionary conferences attended by all missionaries serving in a particular area. The data were collected individually from each subject in a classroom. The attriters back in the western United States were found through lists of returned missionary organizations which included virtually all who had served during particular times in particular areas of Japan, and also by word of mouth from 
other missionaries. Ninety-two percent of those contacted agreed to participate in the data elicitation, which was done in their home, office, or in an office on a university campus. Of the 14 native speakers of Japanese, seven were students at Brigham Young University, Hawaii. They completed the data elicitation in a university office. The remaining seven were university students in Japan in the same age range, who were met in their residences. Since the data from the native speaker subgroups did not differ statistically, they were combined for the analyses.

The L2 Mandarin learner/attriter group consisted of 167 learners (140 male, 27 female), 143 attriters (109 male, 34 female), and a control group of 35 native speakers of Mandarin. The learners in Taiwan were selected randomly at missionary conferences attended by all missionaries serving in a particular area. The data were collected individually from each subject in a classroom. The attriters in the United States were located through organizations for returned missionaries or from an internet site for Chinese-speaking returned missionaries, and were interviewed by telephone. The 35 native Mandarin speakers were Taiwanese students at Brigham Young University, Hawaii and were met in their homes or in a classroom on the university campus.

\section{Elicitation Instruments}

The instrument administered to the L2 Japanese learners/attriters consisted of a set of 24 line drawings, each displaying between one and five exemplars of the pictured object on a $4^{n} \times 6^{n}$ card (see Appendix II, Items 1 to 24). Presented in two alternating randomized orders, there were two items for each of the following twelve classifiers: humans (nin), small animals (hiki), pieces of paper/leaves (mai), pens/tulips (hon), small round pieces of candy (ko), books (satu), vehicles (dai), buildings (ken), birds (wa), pairs of footwear (soku), large animals (too), and letters (tuu). Each subject was given the cards and asked to tell the number of items pictured. The responses were recorded on an answer sheet by the investigator.

In the Chinese data collection sessions, one of three tasks completed was a modified version of the Japanese instrument described above. ${ }^{1}$ In replicating the Japanese elicitation task for the Chinese study, we found that for three of the 12 Japanese counters (mai, hon, hiki) the exemplar pairs elicited two different classifiers from native speakers of Mandarin. For example leaves and pieces of paper, which had been used to elicit the single classifier, mai, in Japanese, fell into two separate semantic categories in Mandarin, pin being used for the classification of leaves; zhang for paper. In these three cases of semantic split of 
the Japanese categories, the new classifications were added to the Chinese version of the task, with a pair of exemplars included for each (the additional items are shown in Appendix II, Items 25 to 30). The Mandarin instrument therefore consisted of 30 line drawings (rather than 24 as for the Japanese), two items for each of the following fifteen classifiers: humans (ge, wei, dui) books (ben), pieces of paper (zhang), small animals (zhi), large animals ( $t a o$, zhi), birds (zhi), pencils/pens (he, zhi), fish (taio), letters (feng), pairs of footwear (shuan), vehicles (liang, tai, bu), buildings (jian, don, zou), small round pieces of candy ( $k e, l i)$, flowers (duo), and leaves (pin). The drawings were presented on a picture sheet mailed or faxed to the subjects. In the telephone interview the learners/attriters were required to orally specify the number of items shown in each drawing. Again, the responses were recorded on an answer sheet by the investigator.

\section{Calculating Suppliance}

Correct classifier suppliance in both the Japanese and Chinese data was determined by the responses of the native speaking control groups. The patterns of correct suppliance between the two languages vary because of basic differences in their systems of classification. The semantic criteria for determining Mandarin classifier classes appear to be more complex than in Japanese and the relations among different classifier categories in Mandarin are more complicated and overlapping. One outcome of the scoring procedures based on these differences is the appearance of higher correct suppliance of classifiers by the Mandarin learners and attriters than by the Japanese. Therefore, because of the language-specific scoring methods used, and in light of Uchida and Imai's (in press) finding that native Japanese children learn the Japanese classifier system earlier than Chinese children learn the Chinese, we suggest a cautionary approach in comparisons made between our two data sets.

In counting suppliance in Japanese, morpho-phonemic deviations from the native-speaker norm (e.g., ippiki vs. nihiki vs. sanbiki) were considered correct as long as the root form of the classifier was supplied. In Japanese, even though the general classifier, tu, can optionally replace specific inanimate classifiers in many instances, the Japanese native speaking control group did not use $t u$ in our elicitation task. It appears that the general classifier is avoided by competent adult speakers, at least in a formal situation when a more specific alternative is available and when the features involved in defining that more specific category are relevant in context. Thus for the Japanese learners/ attriters in the present study, production of the specific classifier was 
required to count as suppliance. In Chinese, however, the responses from the Chinese native speaker control group reveal more complicated relations among different classifier categories. The criterion we adopted for correct suppliance in Mandarin was whether a particular response had been elicited for an item from members of the control group. Thus, because of the variation in native speaker responses, three of the fifteen classifier categories are considered to have three "correct" responses, four of the categories have two acceptable answers, and the remaining eight have a single classifier that counts as correct suppliance.

\section{Results and Discussion \\ Acquisition and Attrition Stages}

Three stages of numeral classifier syntax can be seen in both sets of production data: (1) no classifier in the obligatory context, (2) an unmarked classifier is inserted between numeral and noun, with gradual acquisition of appropriate semantic categories, and (3) correct classifier suppliance. These stages, summarized in Table 1, are reversed in attrition.

Table 1: Stages in the L2 Acquisition and Attrition of Japanese and Mandarin Numeral Classifiers

Acquisition

1. Number $\varnothing$

2. Number-X

3. Number-Specific counter
Japanese Counter for Five Birds/Rabbits

(naked number)

(suppliance rule learned)

(counter specificity) "go (5)

*go-no, "go-hiki

go-wa

\section{Attrition}

4. Number-Specific counter

5. Number- $X$

6. Number Ø

(counter specificity) (gradual loss of specificity) (naked number) go-wa

*go-no, "go-hiki

go

* Incorrect form 
Typical examples of developing classifier choice are given in Chart 1, which shows the most frequent responses for dai over the time cohorts, and in Chart 2 for wa (since only the dominant responses are charted, not all totals reach 100\%). Accessibility of the classifiers is shown for both attrition and acquisition sequences. Notice on these charts that leaving the number "naked, "without a classifier, is a prominent strategy only in the early months of exposure, and becomes preponderant again as the language is lost only after many years of language disuse. Notice further that the suppliance of the general classifier, $t u$, also tends to decrease over the acquisition period as the learners gradually move closer to the native speaker norm of specific classifier use in the elicitation task. We see here in the attrition period an inverse relationship to acquisition, with an increase in general classifier use over time at the expense of the specific dai or wa.

Chart 1: Classifier Suppliance for -dai Elicitation

\section{Acquisition Data}

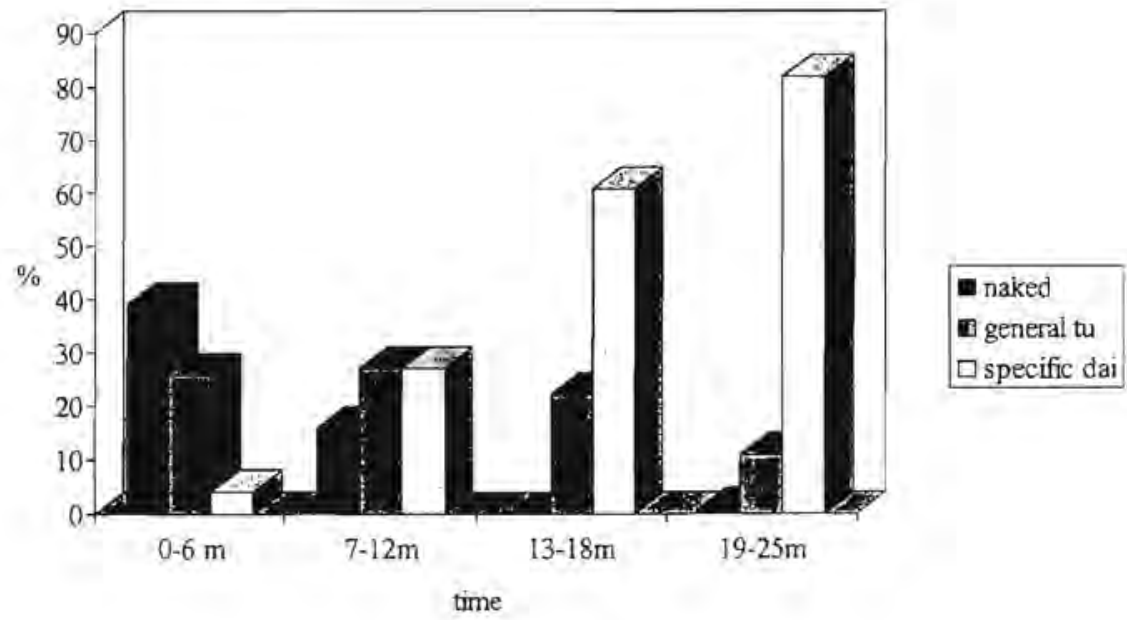

In Chart 2 we see an inverse relationship to acquisition, with an increase in general classifier use over time at the expense of the specific counter dai or wa. The most extreme example of the overgeneralization characteristic of Stage Two is seen in the responses 
given when counting birds because of the availability in the system of the unmarked counter for small animals, hiki. The overextension of hiki in place of the marked specific counter wa begins in the first months of exposure, becomes the dominant response type by the end of the first year, and continues to increase in frequency throughout the learning period. Thus we see that most of these learners fail to acquire wa during two years of extensive exposure, never going beyond Stage Two. Based on our control group data in which two of the fourteen native speakers also used hiki rather than wa for birds (the only category of less than unanimous NS responses in Japanese), we suspect that this may be related to an early stage in the displacement of wa in the language by hiki, just as the counter for fish, kon, rare in contemporary Japanese, has been virtually displaced by this unmarked, highly frequent classifier (Downing, 1996, p. 77).

Chart 2: Classifier Suppliance for -wa Elicitation

Acquisition Data

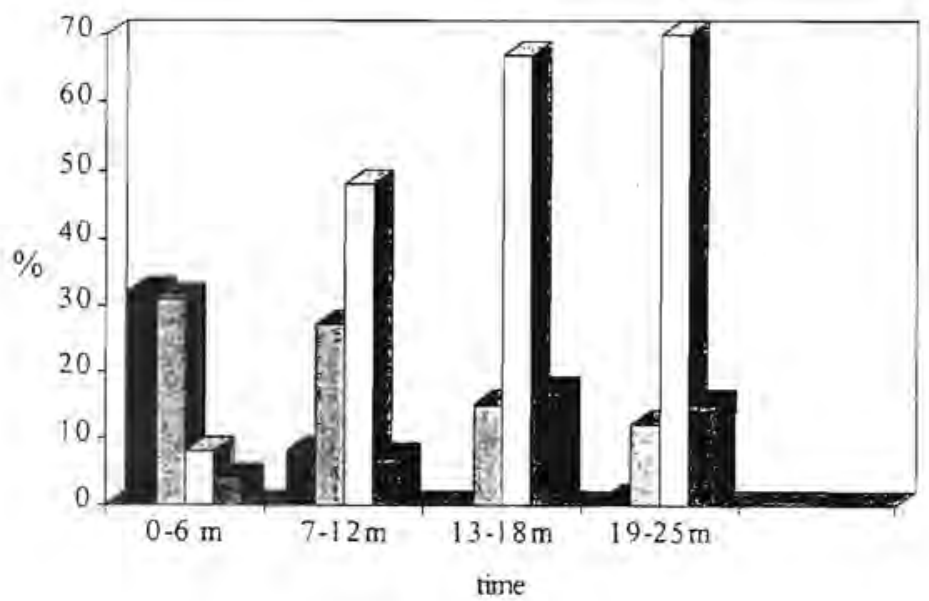

naked

$\square$ general tu 口hiki

Dspecific wa 


\section{Sequences of Semantic Accessibility in Acquisition and Attrition}

The percentages of target language responses for the elicited classifiers are provided in Table 2 for the Japanese data, and Table 3 for the Chinese data. Notice that under Time on each table, the first four columns, representing the Learning Period, indicate the percentage of correct suppliance for 6 -month time cohorts over the two-year exposure period in Japan or Taiwan. On the right side of the table, representing the Attrition Period, are the percentages of correct suppliance for the attriters in time-cohorts based on the number of years since their departure from the target culture. In both the Japanese and Mandarin data sets there are wide disparities between classifiers in their levels of accessibility.

\section{Language Universals and Markedness}

The accessibility patterns in the L 2 data displayed on Tables 2 and 3 show conformity to the constraints of the Numeral Classifier Accessibility Hierarchy: Animate human $>$ Animate non human $>$ Shape $>$ Function. The most accessible non-general classifier category in both acquisition and attrition is the least marked position on the hierarchy, animate: human; in Japanese nin (with its suppletive variants, hitori [one person], and futari [two persons]), and in Chinese ge, wei, or dui. The classifier for small animals also makes an early appearance in interlanguage, hiki in Japanese, and zhi in Chinese. As pointed out above, a strong tendency for overgeneralization of these counters to other non human animates is most pronounced in early acquisition and late attrition. As for the next position on the markedness scale, shape, the three Japanese classifiers, hon, mai, and ko come in relatively early, while in Chinese the status of this larger, fuzzier set of classifiers is less clear. The counters of function included in our elicitation tasks tend to be least accessible of all, and, particularly in Japanese, in some cases do not occur in the data from the majority of learners and attriters. An exceptional case of earlier than predicted acquisition in both Japanese and Chinese, the functional counter for books, may be so because of its high frequency in missionary language.

\section{Frequency in Input}

Inasmuch as numeral classifier frequency data have not been reported for Mandarin, we focus in this section on the evidence from the Japanese data. Notice in Table 2 that the classifiers are arranged according 
Tabie 2: Percent Supoliance of Japanese Numeral Classifiers

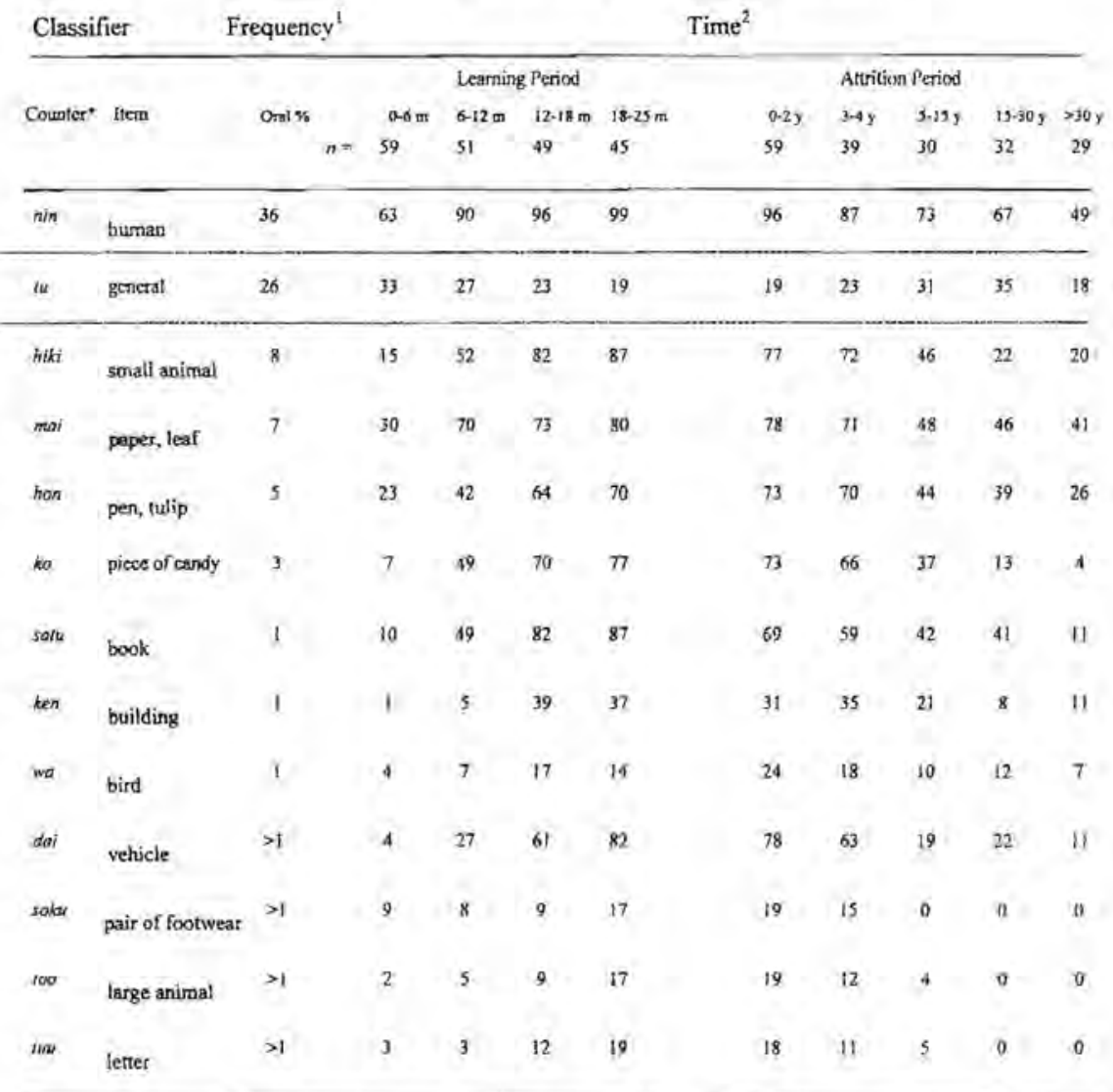

-The counters anc listed in the order of frequency in conversational input.

1. From Downiag (1984).

2. Time for learners indicates the number of months in Japan at the time of data collection; for the atriters the number of years since leaving Japan.

3. Percentages for $t u$ indicate the sabstitution rate of this general classifier in place of the twelve more specific ones which the 24 iterns of the instrument were designed to elicit. 
Table 3: Percent Suppliance of Chinese Numeral Classifiers

\begin{tabular}{|c|c|c|c|c|c|c|c|c|c|}
\hline \multirow{4}{*}{$\begin{array}{l}\text { Classifier } \\
\text { Counter }\end{array}$} & \multirow{4}{*}{ Item } & \multicolumn{8}{|c|}{ Time * } \\
\hline & & \multicolumn{4}{|c|}{ Leaming Period } & \multicolumn{4}{|c|}{ Attrition Period } \\
\hline & & $0-6 \mathrm{~m}$ & $7.12 \mathrm{~m}$ & & $9-25 \mathrm{~m}$ & $n-2 y$ & $3-5$ y 6 & 5.10 y 20 & $2-30 y$ \\
\hline & & 46 & 57 & 25 & 39 & 28 & 25 & 46 & 46 \\
\hline ge, wei, dui & human & 99 & 96 & 98 & 87 & 100 & 100 & 100 & 98 \\
\hline zhi & small animal & 59 & 77 & 88 & 92 & 84 & 72 & 60 & 26 \\
\hline tiao, zht & fish & 33 & 61 & 73 & 85 & 66 & 56 & 44 & 33 \\
\hline zhang & paper & 61 & 88 & 96 & 97 & 79 & 58 & 55 & 33 \\
\hline pin & leaf & 0 & 5 & 12 & 28 & 7 & 6 & 5 & 10 \\
\hline zhi, he & pen & 22 & 61 & 60 & 77 & 59 & 54 & 55 & 26 \\
\hline dao & tulip & 0 & 16 & 20 & 15 & 16 & 14 & 15 & 6 \\
\hline ke, li & piece of candy & 5 & 18 & 26 & 28 & 11 & 6 & 7 & 8 \\
\hline ben & book & 85 & 98 & 98 & 100 & 93 & 92 & 91 & 72 \\
\hline jian, don, zou & building & 6 & 21 & 38 & 61 & 23 & 24 & 18 & 6 \\
\hline $2 h i$ & bird & 38 & 61 & 78 & 86 & 61 & 50 & 43 & 18 \\
\hline tai, liang, bu & vehicle & 6 & 37 & 72 & 90 & 50 & 36 & 22 & 10 \\
\hline shuan & pair of footwear & 9 & 46 & 80 & 86 & 72 & 64 & 62 & 37 \\
\hline tao, zhi & large animal & 51 & 63 & 74 & 86 & 68 & 50 & 44 & 13 \\
\hline feng & letter & 13 & 48 & 74 & 81 & 79 & 68 & 37 & 29 \\
\hline
\end{tabular}

Time for learners indicates the number of months in Taiwan when data were collected; for the attriters the number of years since leaving Taiwan 
to their frequency in oral conversational input, shown as a percentage in the leftmost column. The oral sample upon which the frequency count is based was collected by Downing (1984) from a number of transcribed Japanese conversations and conversational segments which involved a variety of interlocutors. We see in these frequency data that a small number of forms constitute a disproportionately large percentage of actual classifier usage, As pointed out by Downing (1984), although average Japanese native speakers may have a large inventory of forms at their command, only a small number of these commonly play a part in their everyday language use.

As seen in an overview of the acquisition and attrition data in Table 2 , classifier accessibility is quite consistent with a frequency explanation. The most frequent counters, nin and $t u$, are acquired earliest and tend to be retained longest. The next most frequent classifiers, hiki, mai, hon and $k o$, pattern in a second acquisition group. Notice also that the counters which are most resistant to loss over decades of nonuse, nin, tu, hiki, mai, and hon, are the very five that, according to the frequency count, are most numerous in input during the learning period.

With regard to the two Japanese classifiers that were learned more quickly than Downing's (1984) frequency count or markedness considerations would have predicted, satu (the counter for books), and dai (the counter for large mechanical objects), we observe that these classifiers were highly frequent in the learning environment of the subjects. Their daily preoccupation with reading and persuading others to accept and read copies of a book of scripture undoubtedly increased their use of the classifier for books. Similarly, with bicycles as a daily means of transportation and a high level of interest of many in this 19 to 24 age group in mechanical objects such as automobiles, we suspect that the proportion of dai used in their conversations may have also exceeded that reported by Downing.

\section{Regression Hypothesis}

The overall percentages of accuracy for the individual classifiers are compared between the acquisition data and the attrition data for the L2 Japanese in Chart 3, and the L2 Chinese in Chart 4. Notice the similarities in the relative accessibility of the counters in the acquisition and in the attrition data. These views of our two data sets make even more clear what is also evident in Tables 2 and 3, that, in the case of numeral classifiers, those which are most accessible in learning are retained longest, and those which are less accessible are more susceptible to loss. 
Chart 3: Mean Percentages of Classifier Accuracy for Learners and Attriters: Japanese

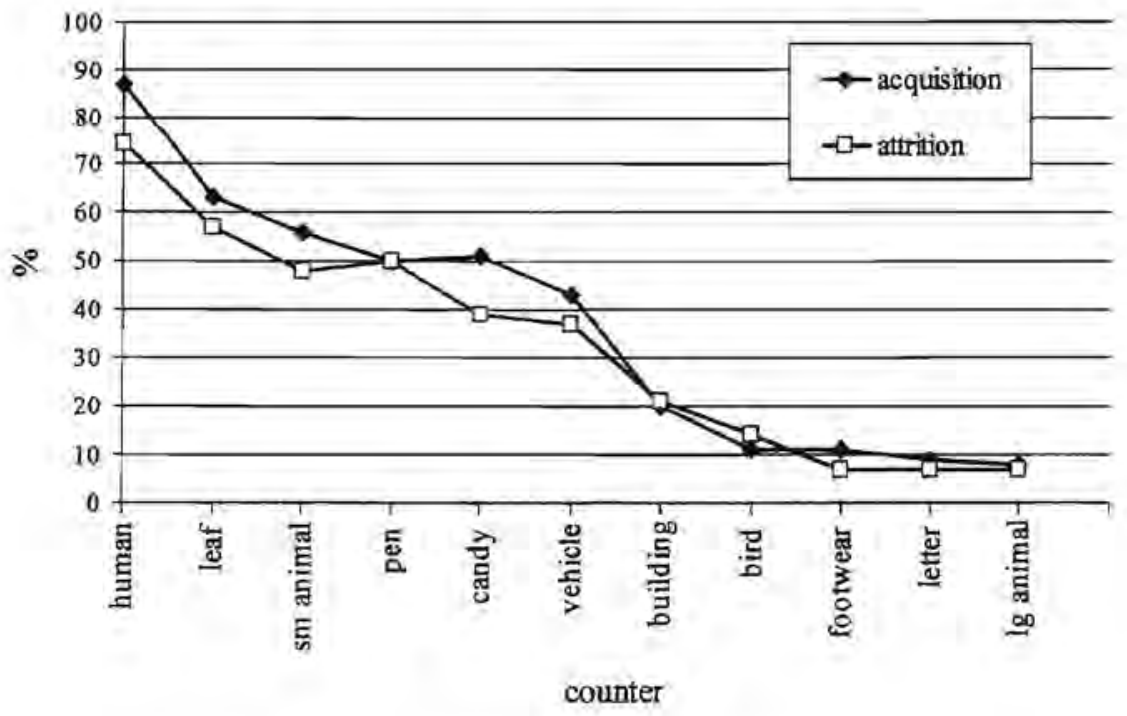

Chart 4: Mean Percentages of Classifier Accuracy for Learners and Attriters: Chinese

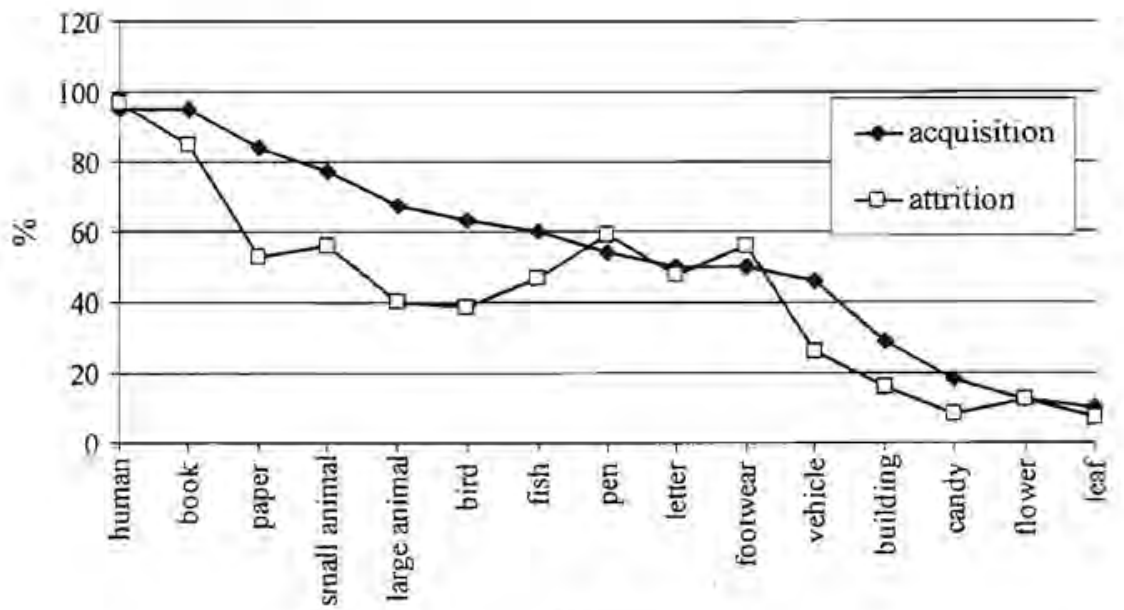

counters 


\section{Conclusion}

In language acquisition a hierarchy of markedness imposes a path of least resistance, a natural contour which can be modulated to some extent by structures of the L1 and L2 (Gass, 1979). In the present study the unpredicted high accessibility of the counter for "book," a highly frequent classifier in the particular population studied, suggests that input frequency can also exert enough influence to modulate the markedness scale. In the search for more definitive evidence about frequency effects we recommend that future studies compare classifier input and acquisition between L2 groups in different learning environments, such as missionaries, migrant workers, classroom learners, and the like.

An original contribution of the present study is the evidence, from both Japanese and Chinese data, for the loss of semantic categories in an inverse order to which they had been learned. Thus, if frequency in input has influenced the acquisition sequence, one might question the occurrence of the same sequence (in reverse order) in the absence of input during attrition. We suggest that stronger neural connections resulting from the high frequency of an item during the learning period may increase the durability of that item after input is discontinued. Longitudinal studies are needed in which input frequency in acquisition is controlled and the course of attrition is carefully tracked.

In the syntax of classifier acquisition, we have established that novice learners at Stage I initially produce no classifiers in their second language. ${ }^{2}$ At Stage Two the learners become aware of the obligatory grammatical role of counters and gradually extract the semantic rules for their use. As in the case of the L1 learners observed by Uchida and Imai (in press), the learning process of the semantic criteria is long and difficult. But unlike the children in Uchida and Imai's study, in the data here the adults vary substantially in the extent to which this is accomplished. A few missionaries may learn all of the semantic categories during the first year while others, including many who are apparently effective communicators in their second language, may attain little knowledge of specific categorization throughout their entire sojourns in Japan or Taiwan.

This individual variation in $\mathrm{L} 2$ classifier specificity may relate to Matsumoto's (1985, p. 86) observation regarding L1 classifier acquisition: Although specific counters are not requisite to efficient communication, children are "governed by their motivation to become fullfledged native speakers expected by the language community. ${ }^{n} \mathrm{Al}-$ though not investigated in the present study, this may also be an important social orientation for second language learners and may drive 
learning from the general to the specific. In the design of future research we recommend the inclusion of affective variables to examine the possibility that learners who are socially distant (Schumann, 1976) or lack integrative motivation (Gardner \& Lambert, 1972) are the ones who continue in the use of more restrictive simplifications (general rather than specific classifiers, or frequent overgeneralization in the use of a few specific ones), features attributed by Meisel (1983) to relatively weak integration into the host society. When it comes to determining how far a learner will proceed toward acquiring and keeping native-speaker norms of specificity in a numeral classifier system, affect may count for a great deal.

Lynne Hansen is Professor of Applied Linguistics at Brigham Young University, Hawaii. She is a regular contributor to the research literature on the progression and regression of languages in bilingualism. Her most recent book is Second Language Attrition in Japanese Contexts (1999, Oxford University Press).

Yung-Lin Chen, a native of Taiwan, received her B.A. degree in TESOL from Brigham Young University, Hawaii in 1999. She is currently working towards a Master's degree in the linguistics department at Brigham Young University in Provo.

\section{Notes}

1. Analyses of data elicited from the other two instruments, numeral classifier recognition tasks, appear in Chen (1999) and Hansen \& Chen (1999).

2. Elicitation data from recently arrived Chinese missionaries in Japan collected as part of a larger study (Hansen, in preparation) indicate that even learners whose first language does contain numeral classification experience an initial stage of classifier non-suppliance in their L2 Japanese.

\section{References}

Adams, K. L., \& Conklin, N. (1973). Toward a theory of natural classification. In C. Corum (Ed.), Papers from the Ninth Regional Meeting, Chicago Linguistic Society (pp.1-10). Chicago: Chicago Linguistic Society.

Allan, K. (1977). Classifiers. Language, 53, 284310.

Berman, R., \& Olshtain, E. (1983). Features of first language transfer in second language attrition. Applied Linguistics, 4, 222-234.

Burling, R. (1973). Language development of a Garo-and English-speaking child. In C. F. Ferguson \& D. I. Slobin (Eds.), Studies of child language development (pp, 69-90). San Francisco: Holt, Rinehart \& Winston. 
Carpenter, K. (1991). Later rather than sooner: Extralinguistic categories in the acquisition of Thai classifiers. Journal of Child Language, 18, 93-113.

Chen, Y-L. (1999). The acquisition and attrition of Chinese numeral classifiers. Senior seminar paper, Division of Languages and Linguistics, Brigham Young University, Hawaii.

Clancy, P. (1986). The acquisition of Japanese. In D. Slobin (Ed.), The crosslinguistic study of language acquisition; Volume 1: The data (pp. 373524). Hillsdale, NJ: Lawrence Erlbaum Associates.

Cohen, A. D. (1975). Forgetting a foreign language. Language Learning, 25, 127-138.

Craig, C. (1986). Noun classes and categorization. Amsterdam: John Benjamins.

de Bot, K, \& Weltens, B. (1991). Recapitulation, regression, and language loss. In H. Seliger \& R. Vago (Eds.), First language attrition (pp. 31-52). Cambridge: Cambridge University Press.

de Bot, K., \& Weltens, B. (1995). Foreign language attrition. Annual Review of Applied Linguistics. Cambridge: Cambridge University Press, 15, 151-164.

Downing, P. (1984). Japanese numeral classifiers: A syntactic, semantic, and functional profile. Unpublished Ph.D. dissertation, University of California, Berkeley.

Downing, P. (1996). Numeral classifier systems: The case of Japanese. Amsterdam: John Benjamins.

Erbaugh, M. S. (1986). Taking stock: The development of Chinese noun classifiers historically and in young children. In C. Craig (Ed.), Noun classes and categorization (pp. 399436). Amsterdam: John Benjamins.

Gandour, J., Petty, S. H., Dardarananda, R., Dechongkit, S., \& Mukangoen, S. (1984). Acquisition of numeral classifiers in Thai. Linguistics, 22, 455-479.

Gardner, R. C., \& Lambert, W. E. (1972). Attitudes and motivation in second language learning. Rowley, MA: Newbury House.

Gass, S. (1979). Language transfer and universal grammatical relations. Language Learning, 29, 327-344.

Hansen, L. (1980). Leaming and forgetting a second language: The acquisition, Ioss and reacquisition of Hindi-Urdu negative structures by English-speaking children. (Ph. D. dissertation, University of California, Berkeley) Dissertation Abstracts International, $42,193 \mathrm{~A}$.

Hansen L. (1999). Not a total loss: The attrition of Japanese negation over three decades. In L. Hansen (Ed.), Second language attrition in Japanese contexts (pp. 142-153). Oxford: Oxford University Press.

Hansen, L. (2000a). Language attrition in contexts of Japanese bilingualism. In M. Noguchi \& S. Fotos (Eds.), Studies in Japanese bilingualism (pp. 353372). London: Multilingual Matters.

Hansen, L. (2000b). Language attrition research archive (LARA). http:// byuh.edu.academics/lang/attritionbiblio/main.htm 
Hansen, L. (in press). Language attrition: The fate of the start. Annual Review of Applied Linguistics, 21.

Hansen, L (in preparation). The learning and loss of L2 Japanese: The missionary experience.

Hansen, L., \& Chen, Y-L. (1999). What counts in the acquisition and attrition of Japanese and Chinese numeral classifiers. Paper presented at 1999 AAAL Conference, Stamford, CT.

Hansen, L., \& Davies, Y. (1998). The acquisition and attrition of Japanese numeral classifiers: Evidence from storytelling data. Paper presented at 1998 ALAA Conference, Brisbane, Australia.

Hansen, L., \& Reetz-Kurashige, A. (1999). The study of second language attrition: An introduction. In L. Hansen (Ed.), Second language attrition in Japanese contexts (pp. 3-20). Oxford: Oxford University Press.

$\mathrm{Hu}, \mathrm{Q}$. (1993). Overextension of animacy in Chinese classifier acquisition. In E. V. Clark (Ed.), The proceedings of the twenty-fifth annual child language research forum (pp. 127-136). Stanford: Center for the Study of Language and Information

Jakobson, R. (1968). Child language, aphasia phonological universals. (A. R. Keiler, Trans.). The Hague: Mouton. (Original work published 1941)

Ken, L. K. (1991). A semantic analysis of young children's use of Mandarin shape classifiers. In A. Kwan-Terry (Ed.), Child language development in Singapore and Malaysia (pp. 98-116). Singapore: Singapore University Press.

Kuhberg, H. (1992). Longitudinal L2 attrition versus L2 acquisition in three Turkish children: Empirical findings. Second Language Research, 8, 138-154.

Matsumoto, Y. (1985). Acquisition of some Japanese numeral classifiers. Papers and Reports on Child Language Development, 24, 79-86.

Meisel, J. M. (1983). Strategies of second language acquisition: More than one kind of simplification. In R. W. Anderson (Ed.), Pidginization and creolisation as language acquisition (pp, 120-157). Rowley, MA: Newbury House.

Olshtain, E. (1989), Is second language attrition the reversal of second language acquisition? Studies in Second Language Acquisition, 11, 151-165.

Sanches, M. (1977). Language acquisition and language change: Japanese numeral classifiers. In B. Blount \& M. Sanches (Eds.), Sociocultural Dimensions of Language Change (pp. 51-62). New York: Academic Press.

Schumann, J. (1976). Social distance as a factor in second language acquisition. Language Learning, 26, 135-143.

Uchida, N., \& Imai, M. (in press). Heuristics in learning classifiers: The implications from the acquisition of the classifier system on the nature of lexical acquisition. Japanese Psychological Research.

Yoshitomi, A. (1992). Towards a model of language attrition: Neurobiological and psychological contributions. Issues in Applied Linguistics, 3, 293-318.

(Received June 5, 2000; revised December 28, 2000) 


\section{Appendix 1}

\section{Elicited Classifiers: Japanese}

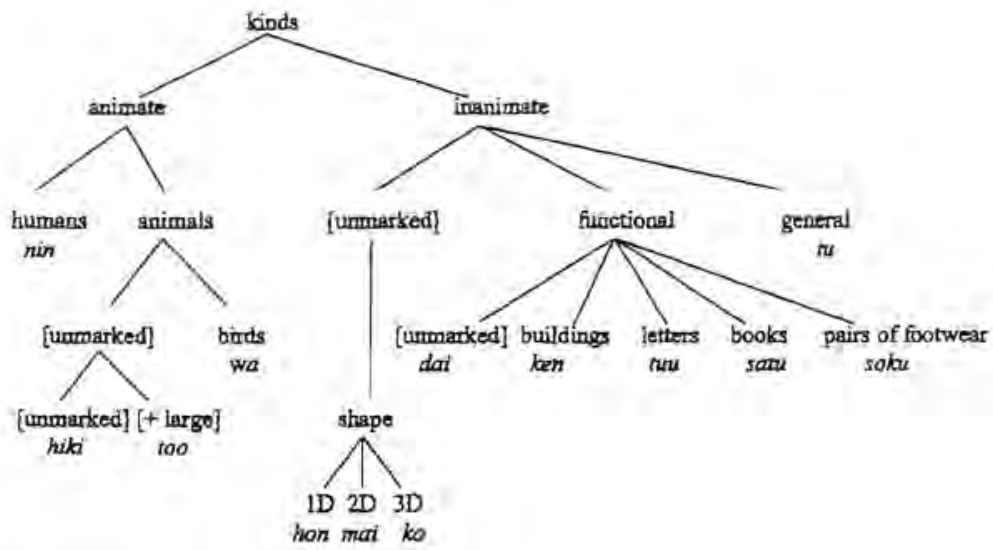

\section{Elicited Classifietrs: Chinose}

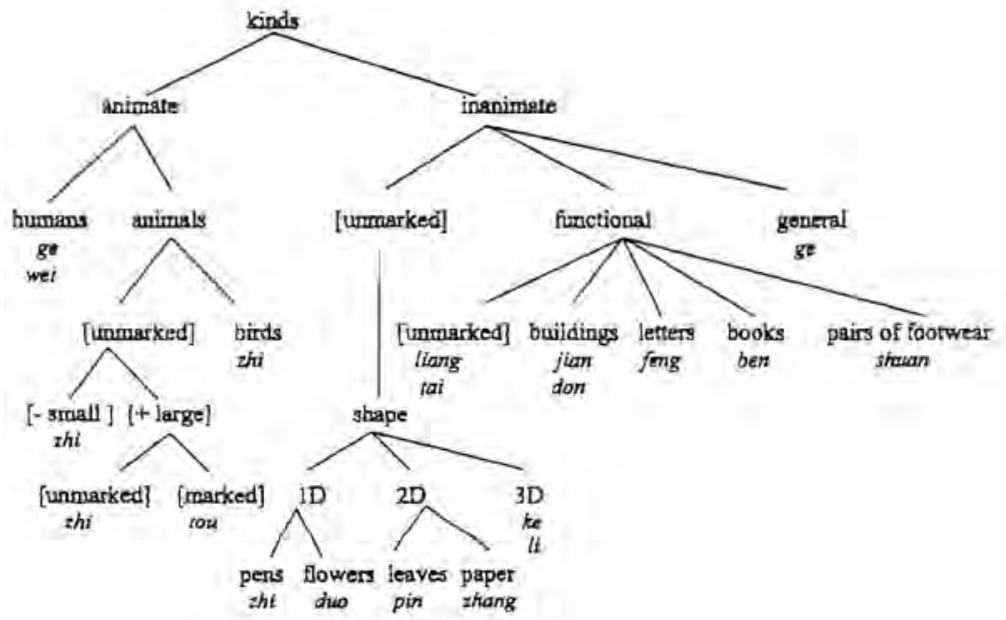


Appendix 2

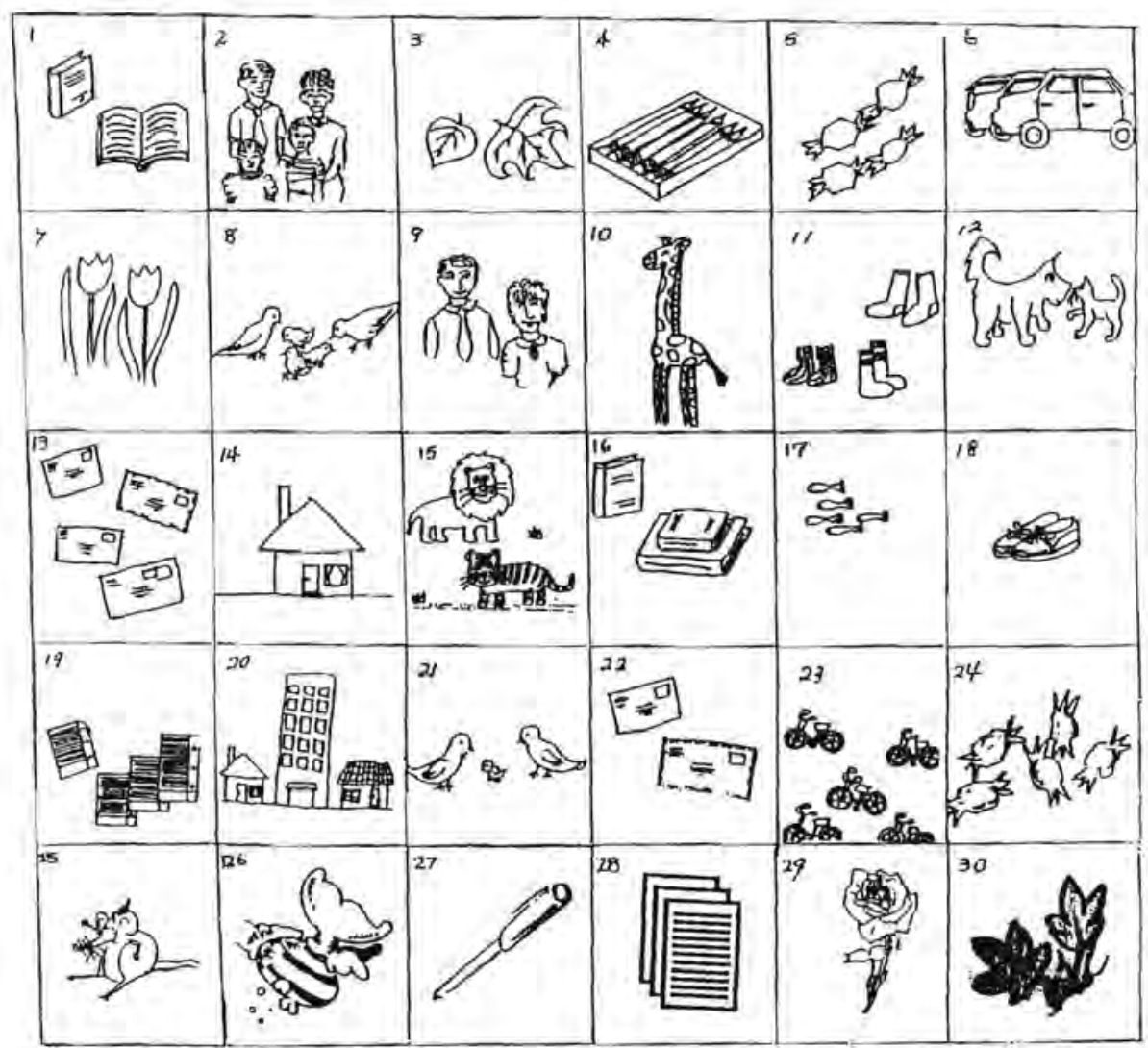

